\title{
The Influence of Family Factors on the Quality of Life of Children With Diabetes Mellitus Type 1 in West Java, Indonesia: A Cross-Sectional Analytic Study
}

\author{
Hotma Rumahorbo $^{1} \&$ Atin Karjatin ${ }^{1}$ \\ ${ }^{1}$ Health Polytechnic of the Ministry of Health, Bandung, West Java, Indonesia \\ Correspondence: Hotma Rumahorbo, Health Polytechnic of the Ministry of Health, Bandung, Dr. Otten 32 \\ Bandung, West Java, Indonesia. E-mail: hotma_rumahorbo@yahoo.com
}

Received: May 20, 2019 Accepted: July 28, 2019 Online Published: August 5, 2019

doi:10.5539/gjhs.v11n10p34 URL: https://doi.org/10.5539/gjhs.v11n10p34

\begin{abstract}
Background: Diabetes is a chronic disease that has a negative impact on the quality of life of children. Family should be a support system to help optimize the quality of life of children with type 1 diabetes mellitus (T1DM).

Purpose: The study aims to analyze the influence of family conflict, number of children in the family, and depression in children on the quality of life of children with T1DM.

Method: The study employed a cross-sectional analytic design with a sample of 51 T1DM children with inclusion criteria being aged 4-18 years and currently undergoing outpatient care at the hospital. The measurement of quality of life used the $\mathrm{KINDL}^{\mathrm{R}}$ instrument, which consists of versions for children and parents. Depression was measured using the Children's Depression Inventory and diabetes-specific family conflict using the Revised Diabetes Family Conflict Scale. Multivariate analysis with multiple linear regression was performed to obtain a prediction model for the quality of life of children with T1DM.
\end{abstract}

Results: The mean total scores of the quality of life for the children's and parents'versionswere76.39 \pm 13.27 and $78.64 \pm 9.38$, respectively. The mean score of diabetes-specific family conflictwas $31.03 \pm 9.28$ with a min-max score of 19-50. Quality of life of children was not different between male and female $(\mathrm{p}=>.05)$. As many as $40 \%$ of the children experienced depression with ameanscoreof $8.28 \pm 5.02$. The quality of life of children for the parent-rated version had a positive correlation with the quality of life of children with $\mathrm{r}=.463$ at $\mathrm{p}=.002$. Depression was negatively correlated with the quality of life of children with $r=-.287$ at $p=.025$. Multivariate analysis shows interactionsbetweenfamily conflict and number of children in the family $(\mathrm{p}=.017)$ and depression $(p=.050)$, both as the main factors affecting the quality of life of children.

Conclusions/Implications for Practice: Family conflict and the number of children in the family and depression in children were predictors of quality of life in children with T1DM. The results of the study have implications for the importance of nursing interventions in improving the ability of families of children with T1DM in handling diabetes-specific family conflict and efforts to prevent depression in children so that children can have better quality of life.

Keywords: T1DM, quality of life, depression, family conflict

\section{Introduction}

It is estimated that the number of children with diabetes mellitus (DM) in the world will experience an increase (Karvonen et al., 2000). In Indonesia, there is no data on the exact number of children with DM. National survey data suggests that in 2007 the prevalence of diabetes was $5.7 \%$, of which more than $70 \%$ of cases were undiagnosed. This estimate hides large intracountry variation. DM is a metabolic disorder characterized by an increase in blood glucose levels caused by insulin dysfunction of pancreatic beta cells (Curtis \& Hagerty, 2002). DM has a negative impact on children's physical, psychological, social, and spiritual conditions (Guthrie, Bartsocas, Jarosz-Chabot, \& Konstantinova, 2007 ; Bas \& Bideci, 2011) and decreases the productivity and quality of life in children (Kalyva, Malakonaki, Eiser, \& Mamoulakis, 2011). Quality of life is an important indicator of patients with chronic diseases, including diabetes (Katon, et al., 2008; Murillo et al., 2017). Health-related quality 
of life is a multi-dimensional construct that is built from a patient's perception of the impact of a disease and its care on aspects of life, including physical, psychological, and social (Lin et al., 2017). Children and adolescents with T1DM have a lower quality of life compared to children and adolescents who are healthy, and depressions are more common in type-1 diabetes (Gendelman et al., 2009).

Diabetes in children does not only have a negative impact on children but also on their parents (Kalyva et al., 2011; Hirose, Beverly, \& Weinger, 2012). Psychological disorders experienced by children will also be experienced by families and vice versa, so that psychological treatment is needed for both children and their parents (Cameron, Northam, Ambler, \& Daneman, 2007; Sieh, Visser-Meily, \& Meijer, 2013). The success of managing child diabetes is highly dependent upon the ability and skills of the family to provide holistic care for children (Klingensmith, Kaufman, Schatz, \& Clarke, 2005; ADA, 2017) because family is a placeforchildren to grow and develop (Dai \& Wang, 2015). Health care providers must realize that the management of children with diabetes is different from that of adults so that family presence is important (Silversmith et al., 2005). Depression in diabetic children is a psychological disorder that often occurs and significantly increases the cost of care compared to diabetic children only (Simon, et al., 2005).

Based on the above descriptions, there are two main objectives of this study, namelyto analyze the influence of family conflict, number of children, and depression in children on the quality of life of children with T1DM and to find a prediction model for quality of life of children. The research hypothesis to be tested is that the higher the conflict and the number of children in the family, the lower the quality of life of children with T1DM; the higher the child's depression score, the lower the quality of life of children with T1DM. The results of this study will be useful for nursing in reorienting the focus of care for children with T1DM and their families, especially in handling family conflict and depression in children.

\section{Methods}

\subsection{Study Design}

The study was conducted with across-sectional analytic design. The sample included a total of 51 children with T1DM who had been outpatients in 2 referral hospitals for the last 2 years, from 2016 to April 2018. The dependent variable is the quality of life of the child version, conflict variables in the family and depression as potential predictors and the number of children in the family as confounding variables.

\subsection{Participants}

Children with T1DMwith the inclusion criteria ofbeing aged 4-18 years and suffering from diabetes for $\geq 6$ months participated in the research along with their parents. The T1DM children participating in this research were outpatients at 2 referral hospitals in West Java. The children were selected based on hospital medical records. The research variables consisted of quality of life of children (children's version and parents' version), diabetes-specific family conflict, number of children in the family, and depression. Children's demographic variables comprised of age, duration of illness, gender, education, age at diagnosis, education level, and number of children in the family. Parents' demographic variables includedage, level of education, and occupation. Most of the parents in this study (95\%) were mothers who cared for and accompanied their children every day. The child and parent demographic data collection formsweredeveloped by the researchers as needed.

\subsection{Instruments}

\subsubsection{Quality of Life}

Quality of life (QoL) of children was measured using the Questionnaire for Measuring Health-Related Quality of Life in Children and Adolescents-Revised Version $\left(\mathrm{KINDL}^{\mathrm{R}}\right)$. The $\mathrm{KINDL}^{\mathrm{R}}$ is a generic instrument for assessing Health-Related Quality of Life in children and adolescents aged 3 years and older, which has been revised and reconstructed (Bullinger, Brütt, Erhart, \& Ravens-Sieberer, 2008; Bullinger et al., 2008). The questionnaire consists of 24 Likert-scale items related to sixdimensions, namely physical health, emotional health, self-esteem, family, friends, and school. There are three different versions of the questionnaire for different age groups, namely for children aged 4-6 years and 7-13 years and adolescents aged 14-18 years. The parent-rated questionnaire consists of one version for parents with children aged 4-6 years and another for parents with children aged 7-18 years, each comprising of 24 items in six dimensions. For children aged $<6$ years, the questionnaire consists of 12 items with six dimensions. The use of the $\mathrm{KINDL}^{\mathrm{R}}$ instrument referenced the instrument user manual (Ravens-Sieberer \& Bullinger, 2000).

\subsubsection{Family Conflict}


This variable was measured using the Revised Diabetes Family Conflict Scale to measure diabetes-specific family conflict based on children's reports. The questionnaire consists of 19 statements. This instrument is intended for children with T1DM who are $>6$ years old; hence, only 47 respondents meeting this age criterion filled in the questionnaire, while 4 respondents were excluded because they were $\leq 6$ years old. The instrument is a powerful psychometric tool used to measure diabetes-specific family conflict in families with children and adolescents with T1DM (Hood et al., 2006).

\subsubsection{Depression in Children}

Measurement of depression in children employed the instrument of Children's Depression Inventory (CDI) (Kovacs, 2003) because the CDI is the most established self-report measure of depressive symptoms for children (Hood et al., 2006). The questionnaire consists of 27 statements. Because the CDI is only intended for participants aged $>6$ years, the questionnaire was only distributed to 47 children.

\subsection{Respondents' Characteristics}

Child demographic variables comprised of age, duration of illness, gender, education, age at diagnosis, and level of education. Parents' demographic variables includedage, level of education, occupation, and number of children in the family. Most of the parents in this study (95\%) were mothers, who cared for and accompanied their children every day. The child and parent demographic data collection forms were developed by the researchers as needed.

\subsection{Data Collection and Statistical Analysis}

All information was obtained directly from primary sources (children and parents) using the previously prepared instruments and user manuals. Because of age, information bias is possible where respondents do not understand the information in the questionnaire. However, researchers have appointed trained enumerators as data collector. Prior to data collection, the researchers explained about the study to the respondents and obtained their consent. The study was conducted by considering the recommendations of the research ethics committee.

Data analysis began with univariate analysis, where numerical data were presented in the forms of mean values, standard deviations, and minimum and maximum values. To proceed to bivariate analysis, a normality test using the Shapiro-Wilk test was first performed on the numerical data, such as quality of life, depression, number of children, and family conflict. The results of the normality test show that the variables of quality of life, number of children, and family conflict were normally distributed $(\mathrm{p}>.05)$, while the variable of depression was not normally distributed $(\mathrm{p}<.05)$. A Pearson correlation test at a confidence level of $95 \%$ was subsequently carried out to see the relationships among the quality of life of children and family conflict, number of children, and depression. Variables with correlation significance value of $\leq .250$ were then included in the modeling using multiple regression analysis. The analysis was intended to build a prediction model for quality of life in children by measuring the influence of family conflict, number of children, and depression. This analysis was also intended to control the possibility of confounding variables and identify possible interaction variables. All respondents can participate fully so that all the expected data can proceed to the analysis stage.

\subsection{Ethical Considerations}

Throughout the whole research process, research ethics were adhered to by the researchers. The research was previously granted an ethical approval from the National Research Ethics Committee No. 31/KEPK/TE/01/VII/17 and permission from the hospitals where the research was conducted No. LB.02.01/X.2.2.2/12538/2018. All participants, both children and parents, gave written consent before the study was conducted.

\section{Results}

\subsection{Demographic Characteristics of Research Participants}

All of the 51 T1DM children and their parents were able to fully participate in the study according to the agreed conditions. The proportion of children aged $4-13$ years reached $64 \%$, where $8.9 \%$ were children aged $4-6$ years, and teenagers aged $14-18$ years made up $35 \%$ of the whole participants. Most children (62.2\%) were female, with a duration of illness $>1$ year as the largest proportion (75.6\%), and $17.8 \%$ of them had had diabetes for $>5$ years. The level of education of parents was mostly (71.1\%) middle to lower education. The characteristics of T1DM children and their parents are presented in Table 1. 
Table 1. Characteristics of T1DM children and their parents

\begin{tabular}{|c|c|c|c|c|c|}
\hline \multirow{2}{*}{ No } & \multirow{2}{*}{ Characteristics } & \multicolumn{4}{|c|}{ Quality of Life (Children's Version) } \\
\hline & & $x_{ \pm \mathrm{SD}}$ & SD & Min & Max \\
\hline \multirow[t]{4}{*}{1} & Participants' age & & & & \\
\hline & 1. 4--6 years & 76.39 & 22.94 & 54.17 & 100.00 \\
\hline & 2. 7- 13 years & 76.04 & 11.59 & 46.88 & 92.71 \\
\hline & 3. 14-18 years & 73.69 & 13.25 & 48.96 & 95.83 \\
\hline \multirow[t]{4}{*}{2} & Duration of illness (Diabetes) & & & & \\
\hline & 1. $<1$ years & 76.66 & 15.69 & 48.96 & 95.83 \\
\hline & 2. $1-5$ years & 74.39 & 12.54 & 46.88 & 100.00 \\
\hline & 3. $>5$ years & 75.65 & 10.84 & 64.58 & 92.71 \\
\hline \multirow[t]{4}{*}{4} & Age at Diagnosis of Diabetes & & & & \\
\hline & 1. $\leq$ byears & 78.56 & 13.47 & 54.17 & 100.00 \\
\hline & 2. 7-13 years & 73.19 & 10.94 & 46.88 & 88.54 \\
\hline & 3. $14-18$ years & 77.86 & 21.87 & 48.96 & 95.83 \\
\hline \multirow[t]{3}{*}{5} & Gender & & & & \\
\hline & 1. Male & 74.02 & 10.59 & 48.96 & 90.63 \\
\hline & 2. Female & 75.95 & 14.24 & 46.88 & 100.00 \\
\hline \multirow[t]{3}{*}{6} & DM History in Family & & & & \\
\hline & 1. Yes & 76.36 & 13.47 & 48.96 & 100.00 \\
\hline & 2. None & 72.51 & 11.12 & 46.88 & 92.71 \\
\hline \multirow[t]{4}{*}{7} & Parents' Education Level & & & & \\
\hline & 1. Primary Education & 73.76 & 15.53 & 48.96 & 95.83 \\
\hline & 2. Secondary Education & 76.76 & 8.45 & 64.58 & 90.63 \\
\hline & 3. Higher Education & 75.32 & 13.41 & 46.88 & 100 \\
\hline \multirow[t]{4}{*}{8} & Parents' Occupation & & & & \\
\hline & 1. Civil Servant/Army/Indonesian Police/Retired & 76.95 & 16.52 & 46.88 & 100.00 \\
\hline & 2. Private Employee & 74.13 & 11.09 & 48.96 & 93.75 \\
\hline & 3. Entrepreneur & 76.25 & 14.52 & 52.08 & 95.83 \\
\hline
\end{tabular}

\subsection{Quality of Life of Children}

Parents' rating of the quality of life of children was generally higher than children's rating of their own quality of life, differing by 2.25 points, but not significantly different $(\mathrm{p}=.20)$. Both children and parents rated the highest scores to friend dimension and lowest on school dimension. More details on the quality of life (QoL) of children rated by children and parents are shown in Table 2 .

Table 2. QoL of children, family conflict, and depression

\begin{tabular}{llll}
\hline Dimensions of Quality of Life & Mean \pm SD & Min-Max & Shapiro-Wilk Normality Test \\
\hline Children's Version $(\mathrm{n}=51)$ & $76.39 \pm 13.27$ & $37.50-97.92$ & .135 \\
\hline Physical Dimension & $74.54 \pm 14.07$ & $50.00-100.00$ & \\
\hline Emotional Dimension & $76.37 \pm 13.17$ & $37.50-100.00$ & \\
\hline Self-Esteem Dimension & $75.15 \pm 19.34$ & $6.25-100.00$ & \\
\hline Family Dimension & $76.37 \pm 17.54$ & $31.25-100.00$ & \\
\hline Friend Dimension & $85.67 \pm 14.61$ & $43.75-100.00$ & \\
\hline
\end{tabular}




\begin{tabular}{|c|c|c|c|}
\hline School Dimension & $72.87 \pm 17.88$ & $25.00-100.00$ & \\
\hline Parents'Version $\quad(n=51)$ & $78.64 \pm 9.38$ & $55.21-95.83$ & \\
\hline Physical Dimension & $70.83 \pm 15.31$ & $31.25-100.00$ & \\
\hline Emotional Dimension & $81.67 \pm 16.50$ & $31.25-100.00$ & \\
\hline Self-Esteem Dimension & $79.17 \pm 17.42$ & $43.75-100.00$ & .101 \\
\hline Family Dimension & $81.81 \pm 12.42$ & $43.75-100.00$ & \\
\hline Friend Dimension & $90.14 \pm 12.53$ & $62.50-100.00$ & \\
\hline School Dimension & $68.19 \pm 10.22$ & $43.75-93.75$ & \\
\hline Depression $(n=47)$ & $8.28 \pm 5.02$ & $2.00-27.00$ & .137 \\
\hline Family Conflict (47) & $31.03 \pm 9.28$ & $19-50$ & .020 \\
\hline
\end{tabular}

\subsection{Correlation Among Family Conflict, Number of Children in Family, and Depression and Quality of Life (QoL) in Children}

Prior to correlation analysis, a Shapiro-Wilk normality test was carried out, and it was found that data on quality of life and depression were normally distributed (see Table 2). Using Pearson correlation analysis, a moderate to strong positive relationship (.463) was found between parents' version of QoL of children and QoL of children. Depression in children had a weak to strong negative relationship with the QoL of children (-.287). Family conflict had a $p=.076$ and number of children $p=.166$, so both were included in the multivariate-analysis modelling. The results in detail are shown in Table 3.

Table 3. Correlationamong QoL of children and family conflict, number of children, and depression

\begin{tabular}{|c|c|c|c|c|}
\hline Variable & $\begin{array}{l}\text { Pearson } \\
\text { Correlation }\end{array}$ & $\mathrm{p}$ & Correlation & Note \\
\hline QoL of Children & 1.00 & & & \multirow{3}{*}{$\begin{array}{l}\text { * Significant at a confidence } \\
\text { level of } 95 \% \text {, both sides }\end{array}$} \\
\hline QoL of Children(Parents' Version) & .463 & $-.002 *$ & $(+)$ moderate to strong & \\
\hline Depression in Children & -.287 & $.025 *$ & (-) weak & \\
\hline Family Conflict & -.287 & $-076^{* *}$ & & \multirow{2}{*}{$\begin{array}{l}* * \quad \text { Included in } \\
\text { analysis/modelling }\end{array}$} \\
\hline Number of Children in Family & -.218 & $.166^{* *}$ & & \\
\hline
\end{tabular}

\subsection{The Influence of Family Conflict, Number of Children in Family, and Depression on Qualify of Life of Children}

Both variables of family conflict and number of children had a $\mathrm{p}=.250$; hence, they were included in the multivariate analysis with multiple linear regression for modeling.

The results of modeling show there was an interaction between the variables of family conflict and number of children in the family, where the R-square change $=>10 \%$, so model 4 was found to be effective at predicting quality of life in children with T1DM.

To find out whether the model conforms to the assumptions of multiple linear regression, the following tests were performed.

1) Existential assumptionwasmet with a residual mean of 0.000 and a standard deviation of 9.648.

2) Independence Assumption was met with a Durbin-Watson value of $1.863(<2)$

3) Linearity assumption was metwith an ANOVA score of 0.001

4) Homoscedasticity assumption was met with the spread of dots showing a similar pattern. As the plot, the dots are spread out in a similar pattern and below the diagonal line 0 . Hence, the homoscedasticity assumption was met.

5) Normality test. The point distribution of the normal P-P plot image is relatively close to the straight line indicating the fulfillment of the normality distribution 
6) Multicollinearity Test. Multicollinearity did not occuras can be seen from the tolerance statistics score of less than 0.4 and a VIP of less than 10 .

\subsection{The Final Model}

With all of the multivariate analysis assumptions being met, the final model to predict the quality of life of children is as shown in Table 4.

Table 4. Model summary

\begin{tabular}{|c|c|c|c|c|c|c|c|c|}
\hline & \multirow{2}{*}{$\begin{array}{l}\text { Unst Coeff } \\
\text { B }\end{array}$} & \multirow{2}{*}{$\mathrm{t}$} & \multirow{2}{*}{$\mathrm{p}$} & \multicolumn{2}{|c|}{ Collinearity Statistics } & \multirow{2}{*}{ R-Square } & \multirow{2}{*}{$\begin{array}{l}\text { Durbin } \\
\text { Watson }\end{array}$} & \multirow{2}{*}{ Anova } \\
\hline & & & & Tolerance & VIF & & & \\
\hline Constant & 61.837 & 6.017 & .000 & & & & & \\
\hline $\begin{array}{l}\text { QoL of children } \\
\text { (Parents' version) }\end{array}$ & .350 & 2.799 & .008 & .991 & 1.009 & & & \\
\hline Depression in children & -.670 & -2.034 & .050 & .972 & 1.029 & & & \\
\hline $\begin{array}{l}\text { Interaction } \quad \text { (family } \\
\text { conflict*number of children) }\end{array}$ & -.081 & -2.502 & .017 & .979 & 1.021 & 0.373 & 1.863 & 0,001 \\
\hline
\end{tabular}

\section{With the following linear equation model}

Quality of life of children: $61.837+0.350$ Quality of life of children (parents' version)-0.081 interaction (Number of children*family conflict)- $\mathbf{0 . 6 7}$ depression in children

The final multivariate modeling displayed in Table 4shows that quality of life (parents' version), family conflict, and number of children and depression in children are predictors of the quality of life of children with T1DM and the overall variables can explain the quality of life of children with T1DM by $37.3 \%$. The positive $(+)$ effect of quality of life of children (parents' version) on the quality of life of children is obtained after the influence of depression and family conflict and number of children is controlled. Each increase in the score of quality of life of children (parents' version) by 1 unit will increase the score of quality of life of children by 0.350 , with a value of $p$ $=.000$.

On the other hand, the negative influence (-) of child depression on the quality of life of children is obtained after the variablesofquality of life of children (parents' version) and family conflict and number of children are controlled. Each increase by 1 unit in the score of depression in children will reduce the score of quality of life of children by 0.67 with a value of $p=.50$. The interaction between family conflict and number of children has a negative influence (-) on the quality of life of children after the variablesofquality of life of children (parents' version) and depression in children are controlled. Each increase in the scores of family conflict and number of children in the family will reduce the score of quality of life of children by 0.081 with a value of $p=.017$. The variables that greatly influence the score of quality of life of children are family conflict and number of children in the family and depression in children.

\section{Discussion}

This study provides important evidence for the urgency of health care providers to pay attention to the condition of families with children with diabetes. The study demonstrates that illness-specific family conflictwasnegatively correlated with the quality of life of children. It was also negatively correlated with the number of children in the family. Moreover, both of the factors (interaction variables) were strong predictors of the quality of life of children with T1DM. Depression in children also serves as a predictor.

The finding indicating that diabetes-specific family conflict was negatively correlated to the quality of life of diabetic children is in accordance with that of previous studies (Cameron et al., 2007; Laffel et al., 2003). Diabetes-specific family conflict is a negative condition caused by the less than optimal family resilience in caring for children andfamily's lack of knowledge and skills, especially parents, in caring for children (Klingensmith, Kaufman, Schatz, \& Clarke, 2005). Family conflict causes depression in diabetic children (Hood et al., 2006). Family conflict can arise due to financial constraints (Pediatrics \& American Academy of Pediatrics, 2003). Diabetic children who experience depression increase the cost of health financing because of the increased 
frequency of doctor visits and use of drugs (Holt, De Groot, \& Golden, 2014);as a result, depression in children with diabetes becomesa complicating variable on the quality of life of children.

In line with the results of previous studies, the number of children in the family also had a negative correlation with the quality of life of children (Özyazıcıŏglu, Avdal, \& Sağlam, 2017). The number of children in the family triggers and aggravates conflicts in the family because each family member needs time and attention from parents and other family members; hence, more members in the family means more time and attention needed (Dai \& Wang, 2015); meanwhile, diabetic children need more attention.

Providing holistic care for children with diabetes is one of the family's tasks (Geisler et al., 2012; Dai \& Wang, 2015; Pereira, Berg-Cross, Almeida, \& Machado, 2008). Poor glycemic control and ability of children in self-care are associated with a decrease in the quality of family functions. Family processes also play a major role in the development of depression in adolescents with diabetes (Moore, Hackworth, Hamilton, Northam, \& Cameron, 2013). The negative correlation of depression in children with T1DM with the quality of life of children found in the present study is also in accordance with the result of previous studies (Egede \& Ellis, 2010). Depression is a condition that describes a decrease in the interest and ability to carry out daily activities, fatigue, and difficulty in concentrating (Avianti, Desmaniarti, \& Rumahorbo, 2016). Therefore, when depression occurs in a child with diabetes, it will worsen the condition of the disease because the child will have difficulty to take such therapy as insulin injection, physical exercise, diet, and monitoring of blood glucose levels (Chen et al., 2017; Moore et al., 2013). Meanwhile, a study shows that the quality of life of children with T2DM is better in children who do physical exercise $\geq 30$ minutes and who routinely monitor blood glucose every day (Anderson et al., 2017). Depressed teenagers also exhibit poor performance in their communication and overall roles (Chen et al., 2017); however, psychological therapy yields better results in children and adolescents with diabetes than in adults (Winkley, Landau, Eisler, \& Ismail, 2006). Children with T1DM who experience severe depression are at risk of being hospitalized due to complications of the disease (Hood et al., 2006). Depression correlates with poor self-care ability related to poor family function, blood glucose control, and recurrence of complications of ketoacidosis $(8,10)$ and is a serious comorbid that worsens quality of life, high cost of living, complications, and decreased productivity; thus, depression must be prevented and minimized.

Based on the results of this study, we can recommend effective forms of intervention that can improve the quality of life of diabetic children. As suggested by Curtis and Hagerty (2002), continuous educational interventions are effective in managing children with diabetes and psychoeducational interventions can increase parental involvement in glycemic control and family conflict management (Katz, Volkening, Butler, Anderson, \& Laffel, 2014). Educational interventionsforparents are also recommended in the treatment of T1DM children in Indonesia (Tridjaya AAP et al., 2015)

The implications of this study highlight the needs of families with diabetic children for effective interventions in managing diabetes-specific family conflict as well as building family capacity to prevent and control depression that occurs in children with diabetes. In addition, more accessible information and optimal support for children are needed to optimize quality of life of children with diabetes.

\subsection{Limitations}

The design employed was a cross-sectional study, with a limited number of samples (51 T1DM children and their parents). Because of the limited information available about T1DMchildren and the limited number of subjects seeking treatment, the study only tested three independent variables, namely diabetes-specific family conflict, number of children in the family, and depression in children.

\section{Conclusions}

The results of multivariate analysis show that family factors, especially the interaction between diabetes-specific family conflict and the number of children in the family, were the main predictors of quality of life of children with T1DM. Depression was negatively correlated to and adversely affected quality of life of children. The quality of life of children in the children's and parents'versionswaspositivelycorrelated.Nurses can develop psychoeducation interventions in helping children and parents

An effective model to predict quality of life of children with T1DMisas follow: $61.837+\mathbf{0 . 3 5 0}$ quality of life of children (parents' version) - 0.081 interaction (number of children*family conflict) - 0.67 depression in children.

Family conflict and depression in children can be overcome by psychoeducational interventions for children and parents as an effort to optimize the quality of life of children. 


\section{Acknowledgments}

This study was financially supported by the Health Ministry's Human Resource Development Center of the Republic of Indonesia in 2018.

\section{Competing Interests Statement}

The authors declare that they have no competing interests.

\section{References}

American Diabetes Association. (2017). Childrenandadolescents. Sec. 12. In Standards of Medical Care in Diabetesd 2017. Diabetes Care, 40(Suppl. 1), S105-S113.

Anderson, B. J., Laffel, L. M., Domenger, C., Danne, T., Phillip, M., Mazza, C., ... \& Mathieu, C. (2017). Factors associated with diabetes-specific health-related quality of life in youth with type 1 diabetes: The global teens study. Diabetes Care, 40(8), 1002-1009. https://doi.org/10.2337/dc16-1990

Avianti, N., Desmaniarti, Z., \& Rumahorbo, H. (2016). Progressive Muscle Relaxation Effectiveness of the Blood Sugar Patients with Type 2 Diabetes. Open Journal of Nursing, 06(03), 248-254. https://doi.org/10.4236/ojn.2016.63025

Bas, V. N., \& Bideci, A. (2011). Evaluation of factors affecting quality of life in children with type 1 diabetes mellitus. Journal of Diabetes \& Metabolism, 02(08), 1-5. https://doi.org/10.4172/2155-6156.1000154

Bullinger, M., Brütt, A. L., Erhart, M., \& Ravens-Sieberer, U. (2008). Psychometric properties of the KINDL-R questionnaire: Results of the BELLA study. European Child and Adolescent Psychiatry, 17(SUPPL. 1), 125-132. https://doi.org/10.1007/s00787-008-1014-z

Cameron, F. J., Northam, E. A., Ambler, G. R., \& Daneman, D. (2007).Routine psychological screening in youth with type 1 diabetes and their parents. Diabetes Care, 30(10), 2716-2724. https://doi.org/10.2337/dc07-0603.Abbreviations

Chen, Q., Du, W., Gao, Y., Ma, C., Ban, C., \& Meng, F. (2017). Analysis of family functioning and parent-child relationship between adolescents with depression and their parents. Shanghai Archives of Psychiatry. https://doi.org/10.11919/j.issn.1002-0829.217067

Curtis, J. A., \& Hagerty, R. N. (2002). Managing diabetes in childhood and adolescence.Can Fam Physician, 48, 499-509.

Dai, L., \& Wang, L. (2015). Review of Family Functioning. Open Journal of Social Sciences, 03(12), 134-141. https://doi.org/10.4236/jss.2015.312014

Egede, L. E., \& Ellis, C. (2010). Diabetes and depression: Global perspectives. Diabetes Research and Clinical Practice. https://doi.org/10.1016/j.diabres.2010.01.024

Geisler, A., Lass, N., Reinsch, N., Uysal, Y., Singer, V., Ravens-Sieberer, U., \& Reinehr, T. (2012). Quality of life in children and adolescents with growth hormone deficiency: Association with growth hormone treatment. Hormone Research in Paediatrics, 78(2), 94-99. https://doi.org/10.1159/000341151

Gendelman, N., Bishop, F., Paul Wadwa, R., McFann, K., Kinney, G., Maahs, D. M., ... Rewers, M. (2009). Prevalence and correlates of depression in individuals with and without type 1 diabetes. Diabetes Care, 32(4), 575-579. https://doi.org/10.2337/dc08-1835

Guthrie, D. W., Bartsocas, C., Jarosz-Chabot, P., \& Konstantinova, M. (2007). Psychosocial Issues for Children and Adolescents With Diabetes: Overview and Recommendations. Diabetes Spectrum, 16(1), 7-12. https://doi.org/10.2337/diaspect.16.1.7

Holt, R. I. G., De Groot, M., \& Golden, S. H. (2014). Diabetes and depression. Current Diabetes Reports. https://doi.org/10.1007/s11892-014-0491-3

Hood, K. K., Huestis, S., Maher, A., Butler, D., Volkening, L., \& Laffel, L. M. B. (2006). Depressive symptoms in children and adolescents with type 1 diabetes: Association with diabetes-specific characteristics. Diabetes Care, 29(6), 1389-1391. https://doi.org/10.2337/dc06-0087

Kalyva, E., Malakonaki, E., Eiser, C., \& Mamoulakis, D. (2011). Health-related quality of life (HRQoL) of children with type 1 diabetes mellitus (T1DM): Self and parental perceptions. Pediatric Diabetes. https://doi.org/10.1111/j.1399-5448.2010.00653.x

Karvonen, M., Viik-Kajander, M., Libman, I., LaPorte, R., Tuomilehto, J., Moltchanova, E., ... Tuomilehto, J. 
(2000). Incidence of childhood type 1 diabetes. Diabetes Care, 23(10), 1516-1526. https://doi.org/10.2337/diacare.23.10.1516

Katz, M. L., Volkening, L. K., Butler, D. A., Anderson, B. J., \& Laffel, L. M. (2014). Family-based psychoeducation and care ambassador intervention to improve glycemic control in youth with type 1 diabetes: a randomized trial. Pediatr Diabetes, 15, 142-150. https://doi.org/10.1111/pedi.12065

Klingensmith, G., Kaufman, F., Schatz, D., \& Clarke, W. (2005). Diabetes care in the school and day care setting. Diabetes Care. https://doi.org/10.2337/diacare.28.suppl_1.S43

Lin, C. Y., Lee, T. Y., Sun, Z. J., Yang, Y. C., Wu, J. S., \& Ou, H. T. (2017). Development of diabetes-specific quality of life module to be in conjunction with the World Health Organization quality of life scale brief version (WHOQOL-BREF). Health and Quality of Life Outcomes, 15(1), 1-10. https://doi.org/10.1186/s12955-017-0744-3

Ludman, E., \& Ciechanowski, P. S. (2008).Outcomes in patients with depression and diabetes.Long-Term Effects on Medical Costs of Improving Depression Outcomes in Patients with Depression and Diabetes, 31(6), 2-11. https://doi.org/10.2337/dc08-0032.Long-Term

Moore, S. M., Hackworth, N. J., Hamilton, V. E., Northam, E. P., \& Cameron, F. J. (2013). Adolescents with Type 1 Diabetes: Parental perceptions of child health and family functioning and their relationship to adolescent metabolic control. Health and Quality of Life Outcomes. https://doi.org/10.1186/1477-7525-11-50

Özyazıcıoğlu, N., Avdal, E. Ü., \& Sağlam, H. (2017). A determination of the quality of life of children and adolescents with type 1 diabetes and their parents. International Journal of Nursing Sciences, 4(2), 94-98. https://doi.org/10.1016/j.ijnss.2017.01.008

Soewondo, Ferrario, A., \& Tahapary, D. L. (2013). Challenges in diabetes management in Indonesia: A literature review. Globalization and Health, 9(1), 1-17. https://doi.org/10.1186/1744-8603-9-63

Ravens-Sieberer, U., \& Bullinger, M. (2000). KINDLR questionnaire for measuring health-related quality of life in children and adolescents.

Schor, E. L., \& American Academy of Pediatrics Task Force on the Family. (2003). Family pediatrics: Report of the task force on the family. Pediatrics, 111(6), 2541-1571. https://doi.org/10.1542/peds.111.6.S1.1541

Tridjaya AAP, B., Yati, N. P., Faizi, M., Marzuki, A. N. S., Moelyo, A. G., \& Soesanti, F. (2015). Konsesus Nasional Pengelolaan Diabetes Melitus tipe 1. Original work published in Indonesia

Wayne, J. K., Joan, E. R., Michael, V. K., Elizabeth, H. B., Lin, E. L., \& Paul, S. C. (2008). Long-term effects on medical costs of improving depression outcomes in patients with depression and diabetes. Long-Term Effects on Medical Costs of Improving Depression Diabetes Care, 31(6), 2-11. https://doi.org/10.2337/dc08-0032.Long-Term

Winkley, K., Landau, S., Eisler, I., \& Ismail, K. (2006). Psychological interventions to improve glycaemic control in patients with type 1 diabetes: Systematic review and meta-analysis of randomised controlled trials. British Medical Journal, 333(7558), 65-68. https://doi.org/10.1136/bmj.38874.652569.55

\section{Copyrights}

Copyright for this article is retained by the author(s), with first publication rights granted to the journal.

This is an open-access article distributed under the terms and conditions of the Creative Commons Attribution license (http://creativecommons.org/licenses/by/4.0/). 